\title{
Téoros
}

Revue de recherche en tourisme

\section{Québec : des atouts gardés secrets}

\section{Michel Zins}

Volume 12, numéro 1, mars 1993

Québec, capitale et région touristiques

URI : https://id.erudit.org/iderudit/1078192ar

DOI : https://doi.org/10.7202/1078192ar

Aller au sommaire du numéro

Éditeur(s)

Université du Québec à Montréal

ISSN

0712-8657 (imprimé)

1923-2705 (numérique)

Découvrir la revue

Citer ce document

Zins, M. (1993). Québec : des atouts gardés secrets. Téoros, 12(1), 2-2.

https://doi.org/10.7202/1078192ar d'utilisation que vous pouvez consulter en ligne.

https://apropos.erudit.org/fr/usagers/politique-dutilisation/ 


\title{
Présentation
}

\section{Québec : des atouts gardés secrets}

\author{
Michel Zins
}

Un numero spécial de Téoros consacré a Québec et à sa région constitue-til enfin une reconnaissance officielle de leur vocation touristique? Cette question, en clin d'oeil, n'est cependant pas le pur fruit d'un esprit sarcastique! Citoyen de la région de Québec. professeur a I Université Laval et consultant en tourisme depuis plus de 15 ans, ce n'est qu'entre 1987 et 1989 que i'ai découvert, en dirigeant les consultations et études devant conduire au plan de développement touristique de la grande région de Ouébec, le potentiel varié et la richesse de Québec et de sa régron limitrophe, qui dépasse largement le Cháteau Frontenac et la Place Royale. Mais jai egalement pu constater combien, malgré un produit touristique impressionnant et des résultats forts honorables, Québec hésitait toujours face à sa vocation tounstique, et n'obtenait encore que peu de consideration au niveau provincial face a Montréal.

Ses atouts touristiques, Québec les garde, dirait-on, secrètement voire jalousement, et ne les joue pas sur l'échiquier qui pourrait et devait è tre le sien, le marché mondial des amateurs de lieux uniques, riches d'histoires ou de nature. Riche d'histoire, de culture et d'architecture, Québecet sarégionle sont. EtI'UNESCO le reconnaitt. Riche de natureellesle sont également parle fleuve Saint-Laurent, les Des quion y trouve a proximité, les contreforts des Laurentides et Thiver.

Pierre Labrie expose dans son article la vraie dimension du tourisme a Québec et dans sa région, etreprend/'essentiel du diagnostic et des enjeux que nous avions identifiés lors de l'exercice d'analyse, de consultation et de planification effectué de 1987 à 1989.

Jajouterai, pour résumer, que le potentiel touristique de la région de Québec est indiscutable, et que le produit qu'elle offre dépasse celui de bon nombre de ses concurrentes en qualité, en diversité et en authenticité. II lui manque cependant encore, pour en tirer tous les bénéfices, la force de conviction de son industrie, de ses citovens et du gouvernement du Québec. Cette conviction ne viendra cependant pas sans des choix importants quant au type de tourisme recherché, le dépassement du localisme et du provincialisme qui ont trop souvent caractérisé les débats et entreprises touristiques à Québec et dans sa région, pour enfin naviguer sur les marchés internationaux où se trouve sa véritable place. Des moyens devront être mis en oeuvre pour prendre cette place, et un effort de coordination et d'organisation de l'indus trie elle-même est requis, pour permettre au tounste de vivre la véritable expérience que peut lui offrir la région de Québec, sans pour autant nure au cadre de vie de ses citovens.

Les articles de Jean-Paul LAMlier, maire de Québec, et Jacques Demers, président du Secrétariat de la Capitale, nous permettent de penser que la conviction requise du pouvoir local et provincial ne sont pas impensables. Ouébec commevile de ses citovenset du patrimoine mondial, et Québec capitale du Québec et des Québécois, ne peut pas et ne devrait pas rester un secret touristique bien gardé encore longtemps, etce, autant pour des raisons économiques que pour des raisons de fierté.

Monsieur Claude Dubé illustre parfaitement l'ambiguité de la relation entre Québec et le tourisme, mais décritaussiun tourisme carac térisé par les autobus que Québec nia pas choisi et ne devrait pas choisir, car elle mérite plus quíune visite aseptisée de deux heures. Surtout sil'on considere que ce type de tourisme n'est pas, loin s'en faut, le plus rentable et le moins polluant. Ilest encore moins le tourisme de l'svenir.

André Langlois nous présente un autre exemple de ce type de problématique: celur de la vocation touristique des événements cette fois, de la place qu'il faut faire aux touristes dans ces événements, et des critères a retenir dans leur organisation pour en maximiser les retombées touristiques, en particuher dans le choix de la période durant laquelle ils se déroulent. Les retombées touristiques du Carnaval sont indiscutables car sans lui, le coeur de Québec verrait moins de monde s'y amuser en févier; mais qu'en est-il des autres événements?

Pierre Bertrandet Julie Jacques présentent les résultats d'une étude qui démontre que par ailleurs, des attraits culturels peuvent être partagés entre touristes et résidents. Ces derniers sont, d'ailleurs, á Québec, des visiteurs réguliers et satisfarts de ces attraits.

Renée Dubé et moi-même révelont aussi, sur la foi des résultats d'une autre recherche, que le Carnaval de Ouébec est un événement éminemment apprécié des touristes, mais également de la grande majorité des residents qui en fréquentent les activités en grand nombre et de façon assidue.

Au-delà des problématiques actuelles reliées à la gestion et au développement du tourisme, Québec et sa région recélent encore de grands potentiels touristiques sous-exploités ou inexploités. JeanClaude Jay-Rayon et Brigitte Morneau attirent l'attention sur une de ces nombrauses facettes non exploitées du tourisme à Québec, dans ce cas, le plan d'eau, les iles et les berges qu'on retrouve dans les environs.

Henri Jamet démontre, quant à lui, chiffres à l'appui, queles croisières sont également un volet du potentiel touristique de Québec qui reste méconnu et sous-exploité.

Jean Lapointe, finalement, dresse un portrait du produit touristique hivernal de la région de Ouebec. La nichesse de ce produit permet d'entrevoir, là, un potentiel de développement en voie de réalisation mais encore mal coordonné et peu connu. Pourtant quelle ville au monde peut offir cet éventail d'activités et d'images hivernales?

Pierre Lemay et Peter Gaudet font le point sur la problématique et le potentiel représentés par la tenue de congrès à Québec. La décision récente de construire un nouveau, ou véntable, centre de congrès vat-il permettre de placer Québec sur la carte des destinations recherchées par les congressistes? Québec et sa région pourront certainement leur offrir un bel environnement.

Pour finir, Jan Lundgren présente une analyse de l'évolution de limage de Québec dans les guides touristiques.

Québec est donc une ville touristique par vacation, car elle est un attrait unique par son site, son architecture et son histoire. Québec doit cependant décider si elle veut devenir une ville de tourisme. Le défi est pour elle et sa région de trouver un tourisme dont il est possible de tirer profit sans perdre son identité et la qualité de vie de ses citovens. Ce défi passe par une volonté vigoureuse de s'affirmer sur des marchés choisis et d'y offrir une expérience unique, et également par un entêtement ả préserver le cachet de toute la région.

Québec et sa région sont un laboratoire touristique interessant, trop peu analysé sans doute, oú émerge peut-être un modèle de gestion du tourisme qui soit profitable à l'économie régionale, enrichissant financierement, culturellement et socialement pour ses citoyens et qui ne nuise pas á la qualité de vie, mais au contraire $y$ contribue par les équipements et les activités qu'elle y apporte. Les écueils á éviter sont cependant nombreux, en particulier lencombrement et la dilapidation du patrimoine naturel et architectural 